九州大学学術情報リポジトリ

Kyushu University Institutional Repository

\title{
Significant improvement of device durability in organic light-emitting diodes by doping both hole transport and emitter layers with rubrene molecules
}

Sakamoto, Gosuke

Department of Functional Polymer Science, Faculty of Textile Science and Technology, Shinshu University

Adachi, Chihaya

Department of Functional Polymer Science, Faculty of Textile Science and Technology, Shinshu University

Koyama, Toshiki

Department of Functional Polymer Science, Faculty of Textile Science and Technology, Shinshu University

Taniguchi, Yoshio

Department of Functional Polymer Science, Faculty of Textile Science and Technology, Shinshu University

他

http://hdl. handle. net/2324/19444

出版情報: Applied Physics Letters. 75 (6), pp.766-768, 1999-08-09. American Institute of Physics

バージョン :

権利関係: Copyright 1999 American Institute of Physics. This article may be downloaded for personal use only. Any other use requires prior permission of the author and the American Institute of Physics. 


\title{
Significant improvement of device durability in organic light-emitting diodes by doping both hole transport and emitter layers with rubrene molecules
}

\author{
Gosuke Sakamoto, Chihaya Adachi, ${ }^{a)}$ Toshiki Koyama, and Yoshio Taniguchib) \\ Department of Functional Polymer Science, Shinshu University, Ueda, Nagano 386-8567, Japan \\ Charles D. Merritt, Hideyuki Murata, and Zakya H. Kafafic) \\ Optical Science Division, Naval Research Laboratory, Washington, DC 20375
}

(Received 7 April 1999; accepted for publication 14 June 1999)

\begin{abstract}
We have developed highly durable organic light-emitting diodes. The basic structure of the diodes is anode/hole injection layer/hole transport layer+dopant/emitter layer+dopant/cathode. Both the hole transport and the emitter layers were doped with the highly fluorescent rubrene molecules. With the doping of both layers, $85 \%$ of the initial luminance was successively maintained even after $1000 \mathrm{~h}$ of continuous operation under constant current driving. Doping of only one of these layers, either the hole transport layer or emitter layer, on the other hand, resulted in shorter lifetime. We mention the possible mechanisms of the doping that enhance the device duration. (C) 1999 American Institute of Physics. [S0003-6951(99)03132-0]
\end{abstract}

The recent development of organic light emitting diodes (OLEDs) has revealed that organic semiconductors have high potential for use as light emitting devices because of their high emission efficiency and various emission colors. ${ }^{1,2}$ Improving the durability of OLEDs under continuous operation, however, is still a significant issue for practical device applications, although various efforts reported in previous studies have improved the durability of the devices by a fair amount. $^{3-10}$

These efforts can be classified into two major areas. First, some of the efforts focused on lowering the carrierinjection barrier between an electrode and an organic layer. For hole injection, the insertion of a thin phthalocyanine ${ }^{11}$ or a starburst polyamine ${ }^{12}$ layer between an anode and a hole transport layer (HTL) is a well-established method for reducing the hole-injection barrier. Furthermore, for electron injection, the reduction of electron injection barrier has been achieved by inserting 0.5 -nm-thick alkaline or alkaline earth compounds between a cathode and an electron transport layer (ETL). ${ }^{13,14}$ These reductions of the injection barrier improved device durability as well as decrease of the driving voltage. $^{15}$

Another significant development resulted from the doping highly fluorescent molecules into emitter layers at a concentration of typically $1-5 \mathrm{~mol} \%$. It was revealed that the doping of emitter layers with fluorescent molecules not only enhanced the electroluminescence (EL) quantum efficiency $\left(\Phi_{\mathrm{EL}}\right)$ by a factor of $1-3,{ }^{11}$ but also considerably enhanced device duration. ${ }^{4-10}$ Even though the mechanism that enhances duration is still unclear, the addition of a small amount of dopant molecules such as quinacridone ${ }^{8}$ derivatives, rubrene, ${ }^{5}$ and perylene ${ }^{7}$ was shown to improve consid-

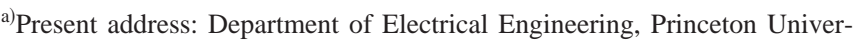
sity, Princeton, NJ 08544; electronic mail cadachi@princeton.edu

${ }^{b)}$ Electronic mail: tany@giptc.shinshu-u.ac.jp

${ }^{c)}$ Electronic mail: kafafi@ccf.nrl.navy.mil
}

erably the device performance. Moreover, Hamada et ll. $^{4}$ recently reported that the control of doping sites dramatically altered duration characteristics. The doping of the HTL, in particular, was found to improve the half decay time of the initial luminance $\left(T_{1 / 2}\right)$ by a factor of 154 compared with that of undoped devices.

In our study, we further expanded the possible doping methods. In addition to the doping of either the EML or HTL, we doped both layers simultaneously. We observed that the doping of both layers greatly enhanced the device duration compared with the doping of either HTL or EML. In this study, we selected $N, N, N^{\prime}, N^{\prime}$ - tetra-tolyl-1, $1^{\prime}$ - diphenylsulphide-4,4' - diamine (TPDS) as the HTL, because TPDS showed inferior duration characteristics in our preliminary study and we can expect large enhancement of the device duration by a doping method. In addition, TPDS has unique optical property, both fluorescence and phosphorescence, which will be useful for a future detailed study of the degradation mechanism due to the triplet excited state. In this letter we mention the possible mechanisms of the duration enhancement.

We fabricated four different cell structures (HIL is a hole injection layer and EML is an emitter layer): Device A: anode/HIL/HTL/EML/cathode; Device B: anode/HIL/ HTL + dopant/EML/cathode; Device C: anode/HIL/ HTL/EML + dopant/cathode; Device D: anode/HIL/HTL +dopant/EML+dopant/cathode. In devices B, C, and D, the doping areas were changed systematically. After the solvent treatment ultrasonically and oxygen plasma ashing of an indium-tin-oxide (ITO) film coated glass substrate $(15 \Omega / \square)$, we successively deposited three organic layers, HIL $(15 \mathrm{~nm})$, HTL $(60 \mathrm{~nm})$, and EML $(75 \mathrm{~nm})$ on the ITO substrate in a vacuum of $2 \times 10^{-6}$ Torr. In this experiment, we set the dopant concentration at $5 \mathrm{~mol} \%$ with respect to the host molecules. A copper phthalocyanine $(\mathrm{CuPc})$ and TPDS were used as the HIL and HTL, respectively (Fig. 1). Tris (8hydroxyquinoline) aluminum (Alq) was used as the EML 


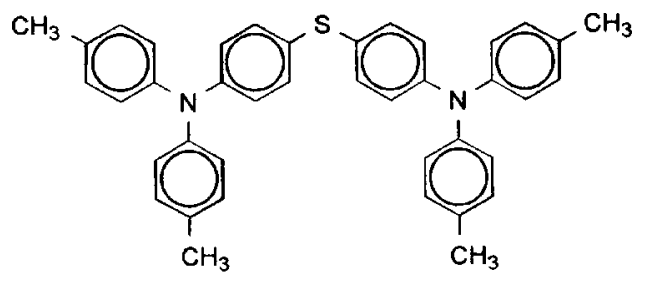

HTM (TPDS)

FIG. 1. Tetra-phenyl-1,1'-diphenylsulphide-4,4'-diamine (TPDS) as HTM.

and rubrene as a guest dopant. Both Alq and rubrene were carefully purified by train sublimation ${ }^{16}$ before use. Finally, a $\mathrm{Mg}-\mathrm{Ag}$ cathode layer $(200 \mathrm{~nm})$ was deposited on the EML. After the fabrication of OLED devices, we immediately transferred the devices to a test tube. ${ }^{17}$ The atmosphere of the tube was replaced with dry nitrogen $\left(\mathrm{N}_{2}\right)$ gas three times and kept under an excess pressure of dry $\mathrm{N}_{2}$ with fresh $\mathrm{P}_{2} \mathrm{O}_{5}$ as a desiccant. The characteristics of the OLEDs device durability were examined by applying a constant current density of $J$ $=10 \mathrm{~mA} / \mathrm{cm}^{2}$.

Table I summarizes initial device performance: initial luminance $\left(L_{0}\right)$, initial voltage $\left(V_{0}\right)$, energy conversion efficiency $\left(\Phi_{\text {energy }}\right)$, and EL quantum efficiency $\left(\Phi_{\mathrm{EL}}\right)$ at $J$ $=10 \mathrm{~mA} / \mathrm{cm}^{2}$. In devices B, C, and D, $\Phi_{\mathrm{EL}}$ was $1.62-1.95$ times higher than that of the undoped device (device A). This result is in good agreement with previous reports ${ }^{5,18}$ where $\quad N, N^{\prime}$-diphenyl- $N, N^{\prime}$ - bis(3-methylphenyl)-1, $1^{\prime}$ biphenyl-4, $4^{\prime}$-diamine (TPD) was used as the HTL.

Figure 2 shows luminance decay with time for the four devices. The vertical axis shows normalized luminance $\left(L / L_{0}\right)$, which is luminance divided by the individual initial luminance $\left(L_{0}\right)$. In the undoped device, $T_{1 / 2}$ (the half decay of $L_{0}$ ) was extremely short (only $16 \mathrm{~h}$ ), while $T_{1 / 2}$ was prolonged to $190 \mathrm{~h}$ by doping the HTL (device B). Furthermore, the duration characteristic was significantly improved by doping the EML (device C), and resulted in $T_{1 / 2}$ of over 1000 h. Finally, we observed that the doping of both the HTL and the EML considerably improved the device durability. After the rapid drop of luminance (15\%) during the initial $200 \mathrm{~h}$, constant luminance was successfully maintained even after 1000 h of continuous operation. The inset in Fig. 2 shows the variation of driving voltages over time in the four devices. Although a rapid increase in voltage was observed in device A, the doped devices, devices B, C, and D, showed a rather slow rise after the initial rapid increase within $20 \mathrm{~h}$. In the case of device $\mathrm{D}$, in particular, the voltage increase was well suppressed within $1.1 \mathrm{~V}$ after $1000 \mathrm{~h}$ of continuous operation. Thus, we found that doping both the HTL and the EML

TABLE I. Initial OLED device performance: Initial luminance $\left(L_{0}\right)$, initial voltage $\left(V_{0}\right)$, energy conversion efficiency ( $\Phi$ energy), and EL quantum efficiency $\left(\Phi_{\mathrm{EL}}\right)$ at $J=10 \mathrm{~mA} / \mathrm{cm}^{2}$.

\begin{tabular}{ccccc}
\hline \hline & \multicolumn{3}{c}{$\begin{array}{c}\text { Energy conversion } \\
\text { efficiency }\end{array}$} & $\begin{array}{c}\text { EL quantum } \\
\text { efficiency } \\
\Phi_{\mathrm{EL}} / \%\end{array}$ \\
\hline $\mathrm{A}$ & 302 & 8.6 & 1.10 & 0.93 \\
$\mathrm{~B}$ & 523 & 8.8 & 1.87 & 1.68 \\
$\mathrm{C}$ & 458 & 9.6 & 1.50 & 1.51 \\
$\mathrm{D}$ & 560 & 9.9 & 1.78 & 1.81 \\
\hline
\end{tabular}

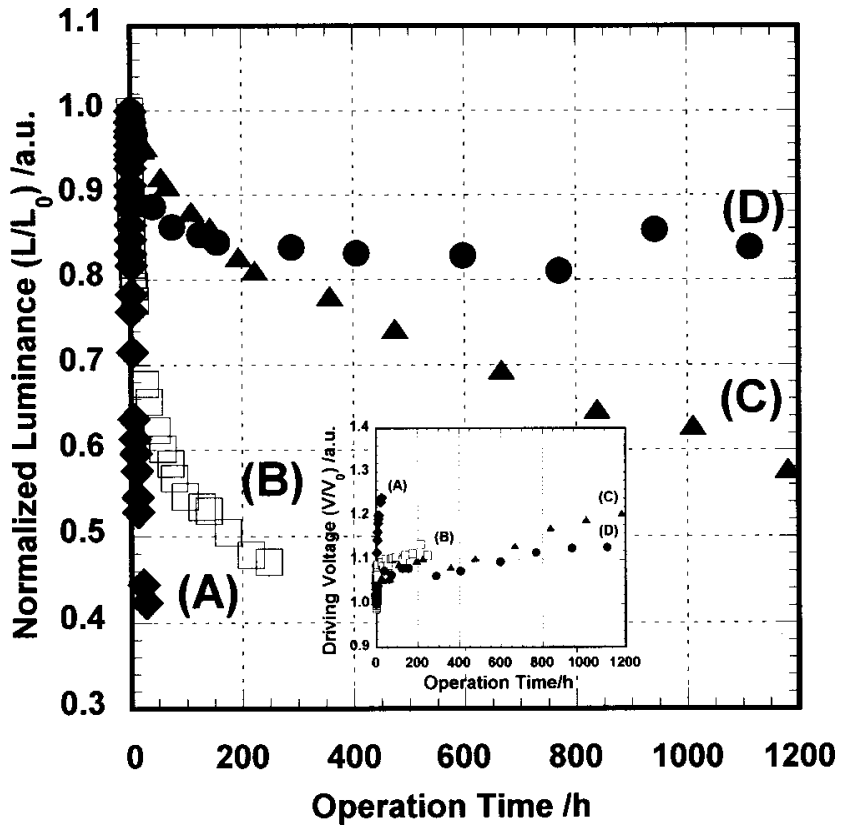

FIG. 2. Normalized luminance $\left(L / L_{0}\right)$-operation time relationship for the four OLED devices with different structures, Devices A, B, C, and D. Inset: Driving voltage-operation time relationship for the four OLED devices.

significantly stabilized both the luminance decay and the voltage increase.

Here, we discuss the possible mechanisms of the durability enhancement resulting from doping. We first mention mechanisms from the aspect of the stability and reactivity of singlet $\left(S_{1}\right)$ and triplet $\left(T_{1}\right)$ excitons of Alq, TPDS, and rubrene molecules, based on the EL spectra of four devices as shown in Fig. 3. In the undoped device (device A), because the EL spectrum is composed of only Alq [Fig. 3(A)], the holes and the electrons recombine primarily inside Alq, and $S_{1}$ and $T_{1}$ excitons of Alq are produced with the branching ratio of 1:3 (if we assume that the prediction of quantum mechanics is correct). ${ }^{19}$ The $S_{1}$ excitons then decay promptly with the radiation of fluorescence (EL) or nonradiatively, and also the $T_{1}$ excitons similarly decay nonradiatively. ${ }^{20}$ In device $\mathrm{C}$ with the rubrene-doped Alq layer, on the other hand, the EL spectrum consisted completely of rubrene's fluorescence, thus holes and electrons were trapped by rubrene molecules and the recombination occurred selectively on them and/or carrier recombination occurred primarily inside Alq, successive creation of the excitons and Förster energy transfer from Alq to a rubrene molecule occurred. In any case, both processes resulted in the rubrene emission. In device B with the rubrene-doped TPDS layer, furthermore, the EL spectrum was composed primarily of the rubrene's fluorescence and the small component of Alq, suggesting that the carrier recombination and EL emission occurred inside the TPDS/rubrene composite and Alq layers. In this device, the duration enhancement factor was smaller $\left(T_{1 / 2}=190 \mathrm{~h}\right)$ than that of device C. Moreover, the definitive enhancement effect of doping both layers appeared in device D, of which the EL was completely composed of the rubrene emission. Based on these EL spectra, we can recognize that the suppression of Alq's states resulted in the enhancement of the device duration, suggesting that the excited states of rubrene molecules are more stable than that of Alq. Thus, there is a cense or copyright; see http://apl.aip.org/about/rights_and_permissions 

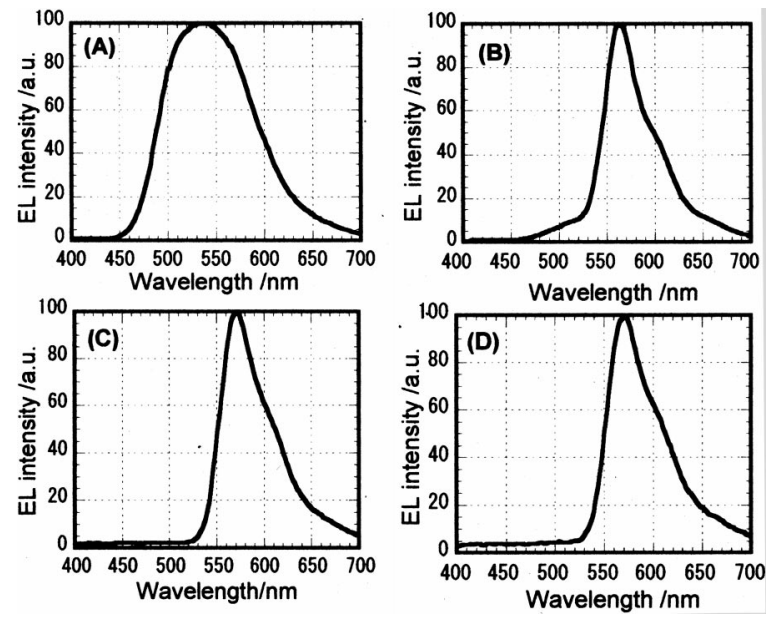

FIG. 3. EL emission spectra of the four OLED devices.

possibility that some of the $S_{1}$ and/or the $T_{1}$ excitons becomes a precursor of (electro-) chemical reactions; for example, the reactions with the radical anion and cation of Alq, producing reaction products that may act as a quencher of Alq excitons. In particular, it has been well established that $T_{1}$ states could be the precursor because of the long lifetime characteristic of $T_{1}$ excitons. ${ }^{21}$

In addition, since doping TPDS layer surely enhanced the device duration (devices B and D), the suppression of the excited states of TPDS is also expected to contribute to the enhancement in a similar manner as the control of Alq excitons. In our previous study, ${ }^{18}$ the penetration of electrons into HTL(TPD) and successive creation of TPD excitons were suggested in a TPD/Alq device. Upon the rubrene doping of a TPD layer, furthermore, the transition of electron hopping sites from TPD to rubrene was confirmed. Thus, it seems feasible that the doped TPDS layer well suppressed the creation of TPDS excitons. Moreover, we have already observed that the molecular structures of the hole transport materials (HTMs) greatly influenced the device duration in undoped devices. ${ }^{22}$ While 4,4'-bis-[N-(1-naphthyl)N-phenylamino $]$-biphenyl $(\alpha \text {-NPD })^{9}$ and $4,4^{\prime}$-bis- $[N$ (9-phenanthyl)- $N$-phenylamino]-biphenyl (PPD) ${ }^{22}$ having condensed aromatic rings were confirmed to exhibit rather stable duration, $N, N, N^{\prime}, N^{\prime}$ - tetra-tolyl-1, $1^{\prime}$-cyclohexyl$4,4^{\prime}$-diamine (TPAC), ${ }^{23}$ and TPDS were revealed to show inferior duration characteristics. It seems probable that such dependencies of HTMs are closely related to the stability of HTM's excited states.

Finally, we should mention that rubrene has been proved to be extremely stable in reduction and oxidation process in a cyclic voltammetry measurement. ${ }^{24}$ This property directly assures that the radical species are stable in carrier transport process, both hole and electron transport, and contributes to the enhancement of the device stability. Also, we should mention that there is another possibility that could enhance the device duration. Besides the electrochemical stability of the host molecules, the enhanced morphology of host layers as a result of the doping should also be considered. It has already been pointed out that doping the host layers stabilizes the morphology of organic thin films. ${ }^{5}$ Doping both layers in particular should lead to further overall stability of the films' morphology. We can expect the suppression of microcrystallization or aggregation of host molecules, which could provide carrier trapping sites, and excess charge carriers $^{25}$ to result in interaction with molecular excitons and their nonradiative decay. ${ }^{26}$

In conclusion, we developed highly durable OLEDs by extending the doping sites; the doping of both HTL and EML. To develop these devices further, we should examine a wide variety of host and dopant materials and their combination, while we should clarify the detailed mechanism of the doping that results in the enhancement in device durability. Recently, the OLED devices having double-emitting layer in which HTL and EML were doped with different dopant molecules were reported to show significant device performance. $^{27,28}$

${ }^{1}$ Organic Light-Emitting Materials and Devices, edited by Z. H. Kafafi (SPIE, Bellingham, WA, 1997), Vol. 3148.

${ }^{2}$ Organic Light-Emitting Materials and Devices 2, edited by Z. H. Kafafi (SPIE, Bellingham, WA, 1998), Vol. 3476.

${ }^{3}$ C. Adachi, K. Nagai, and N. Tamoto, Appl. Phys. Lett. 66, 2679 (1995).

${ }^{4}$ Y. Hamada, T. Sano, K. Shibata, and K. Kuroki, Jpn. J. Appl. Phys., Part 2 34, L824 (1995).

${ }^{5}$ Y. Sato, S. Ichinosawa, and H. Kanai, Proceedings of the Electroluminescence Workshop (Wissenschaft and Technic, Berlin, 1996), p. 255.

${ }^{6} \mathrm{H}$. Nakada and T. Tohma, Proceedings of the Electroluminescence Workshop (Wissenschaft and Technic, Berlin, 1996), p. 385.

${ }^{7}$ S. A. Van Slyke, P. S. Bryan, and C. W. Tang, Proceedings of the Electroluminescence Workshop (Wissenschaft and Technic, Berlin, 1996), p. 195.

${ }^{8}$ T. Wakimoto, Y. Yonemoto, J. Funaki, M. Tsuchida, R. Murayama, H. Nakada, H. Matsumoto, S. Yamamura, and M. Nomura, Synth. Met. 91, 15 (1997).

${ }^{9}$ S. A. Van Slyke, C. H. Chen, and C. W. Tang, Appl. Phys. Lett. 69, 2160 (1996).

${ }^{10}$ J. Shi and C. W. Tang, Appl. Phys. Lett. 70, 1665 (1997).

${ }^{11}$ C. W. Tang, S. A. Van Slyke, and C. H. Chen, J. Appl. Phys. 65, 3610 (1989).

${ }^{12}$ Y. Shirota, Y. Kuwabara, H. Inada, T. Wakimoto, H. Nakada, Y. Yonemoto, S. Kawami, and K. Imai, Appl. Phys. Lett. 65, 807 (1994).

${ }^{13}$ L. S. Hung, C. W. Tang, and M. G. Mason, Appl. Phys. Lett. 70, 152 (1997).

${ }^{14}$ G. E. Jabbour, Y. Kawabe, S. E. Shaheen, J. F. Wang, M. M. Morrell, B. Kippelen, and N. Peygambarian, Appl. Phys. Lett. 71, 1762 (1997).

${ }^{15}$ T. Wakimoto, Y. Fukuda, K. Nagayama, A. Yokoi, H. Nakada, and M. Tsuchida, IEEE Trans. Electron Devices 44, 1245 (1997).

${ }^{16}$ H. J. Wagner, R. O. Loutfy, and C.-K. Hsiao, J. Mater. Sci. 17, 2781 (1982).

${ }^{17}$ C. Adachi, K. Nagai, and N. Tamoto, Jpn. J. Appl. Phys., Part 1 35, 4819 (1996).

${ }^{18}$ H. Murata, C. D. Merritt, and Z. H. Kafafi, IEEE J. Sel. Top. Quantum Electron. 4, 199 (1998).

${ }^{19}$ M. Pope and C. E. Swenberg, Electronic Processes in Organic Crystals (Oxford University Press, New York, 1982), p. 508.

${ }^{20}$ In a separate experiment, it was confirmed that an Alq thin film shows no phosphorescence even at $20 \mathrm{~K}$.

${ }^{21}$ See, for example, N. J. Turro, Modern Molecular Photochemistry (University Science, California, 1991).

${ }^{22}$ G. Sakamoto, C. Adachi, T. Koyama, and Y. Taniguchi, Polym. Preprints, Japan, 47, 1848 (1998).

${ }^{23}$ C. W. Tang and S. A. Van Slyke, Appl. Phys. Lett. 51, 913 (1987).

${ }^{24}$ J. Chang, D. M. Hercules, and D. K. Roe, Electrochim. Acta 13, 1197 (1968).

${ }^{25}$ D. Zou, M. Yahiro, and T. Tsutsui, Appl. Phys. Lett. 72, 2484 (1998).

${ }^{26}$ K. C. Kao and W. Hwang, Electrical Transport in Solids (Pergamon, New York, 1981), p. 485.

${ }^{27}$ M. Arai, K. Nakaya, O. Onitsuka, T. Inoue, M. Codama, M. Tanaka, and H. Tanabe, Synth. Met. 91, 21 (1997).

${ }^{28}$ Z. D. Popovic, S. Xie, N.-X. Hu, A.-M. Hor, and C. Tripp, Material Research Society ('98 Fall Meeting Abstract) p. 383, R9.4, 1998. 